The Bangladesh Veterinarian (2011) 28(2) : 75 - 79

\title{
Effects of age on growth and development of vagina in ISA Brown chickens
}

\author{
K. A. Ferdous*, M. N. H. Parvez and M. T. Rahman ${ }^{1}$ \\ Department of Anatomy and Histology, Faculty of Veterinary and Animal Science, Hajee \\ Mohammad Danesh Science and Technology University, Dinajpur-0531, Bangladesh
}

\begin{abstract}
Structure and postnatal development of vagina in 21 ISA brown chickens was studied at three, 23 and 46 weeks of age. At 3 weeks of age the vagina was narrower and thicker then the uterus. The undifferentiated wall of vagina consisted of low primary mucosal folds lined by simple columnar epithelium to a pseudostratified ciliated columnar epithelium and a connective tissue layer underneath. At three weeks of age, scattered smooth muscle fibres were in the subepithelial connective tissue layer. Rapid structural changes occurred at 23 weeks of age in the adult bird, mucosal folds were narrowed and tongue-shaped. Lamina propia was devoid of glands and contained lymphocytes. Tunica muscularis was well developed at 23 and 46 weeks. (Bangl. vet. 2011. Vol. 28, No. 2, $75-79)$
\end{abstract}

\section{Introduction}

The growth of mature left oviduct plays a significant role in the production of eggs (Kelany et al., 1993). The major part of the female chicken's reproductive system is the oviduct. The oviduct is a long convoluted tube $635-685 \mathrm{~mm}$ long when fully developed, divided into five major sections. The last part of the oviduct is the vagina, made of muscle, which helps in pushing the egg out. The bloom or cuticle is added to the egg in the vagina prior to oviposition. Near the junction of the vagina and the shell gland are deep glands known as sperm host glands. When an egg is laid, some of these sperm can be squeezed out of the glands into the oviduct so that they can migrate further up the oviduct to fertilize an ovum. Remarkably, the sperm remain viable at body temperature. Only a few reports are available on this aspect of vaginal growth and development in ISA Brown chickens. Present study focuses on the morphological events taking place to the vagina.

\section{Materials and Methods}

This study was conducted from March to August 2011 with 21 chickens of 3, 23, and 46 weeks, with seven birds in each group. The birds were slaughtered through ventral neck cutting after recording the live body weight. The oviducts, which were free from gross pathological changes, were obtained for morphometric, histological and histochemical studies. The gross study included the colour, length, weight and

\footnotetext{
*Corresponding author:- E-mail: raby_vet@yahoo.com
} 
diameter of the oviduct. Relative weights were calculated adopting the formula of Federova (1987).

The tissues of the vagina were fixed in $10 \%$ formalin solution, dehydrated in graded alcohol, cleared in xylene, embedded in paraffin and the sections cut at $6 \mu$ thickness using rotatory microtome (Leica Leica, Germany). The histological study analyzed the structure and growth of the epithelium, lamina propria, tubular glands, sperm host glands and tunica muscularis and serosa.

\section{Statistical analyses}

The results were presented as Mean \pm SD of 3 different ages of 7 chickens for each age group in each parameter and the data obtained from various parameters were analyzed by ANOVA using Randomized Complete Block Design (RCBD) (Ali, 1973). The differences between means were compared by $\mathrm{F}$ test for significance $(\mathrm{P}<0.01)$.

\section{Results and Discussion}

The oviduct in the ISA brown chickens was whitish in colour at three weeks and grayish at 23 weeks and pale or yellowish at 46 weeks of age. It was a translucent tube on the left of the coelom, supported by peritoneal folds. The vagina was narrower than the uterus but the wall was thicker. It was located between the third and fifth coccygeal vertebrae and opened caudally to the urodeum of cloaca. In adult bird, it appeared as a short S-shaped tube. Externally vagina was held close together by fibrous bands.

Gross anatomy

Length of the vagina

The mean length of vagina at three, 23 and 46 weeks of age were $0.3 \pm 0.1 \mathrm{~cm}, 6.0$ $\pm 0.1 \mathrm{~cm}$, and $6.1 \pm 0.3 \mathrm{~cm}$, respectively (Table 1). The length of the vagina increased with age. In laying hen, the length is in agreement with the 4 to $12 \mathrm{~cm}$ reported by Giersberg (1922) but not with the report of Taylor and Hertelendy (1960), and Romanoff and Romanoff (1949) who reported a length of $8 \mathrm{~cm}$.

\section{Weight}

The mean weight of vagina was $0.0 \pm 0.0 \mathrm{gm}, 1.0 \pm 0.0 \mathrm{gm}$, and $2.5 \pm 0.1 \mathrm{gm}$ at 3 , 23 and 46 weeks old, respectively (Table 1). Scott (1935) reported the weight of vagina of laying hen as $5 \mathrm{gm}$, inconsistent with the present findings. The weight increased greatly with age.

\section{Diameter}

The mean diameter of vagina at 3,23 and at 46 weeks oldwas $0.4 \pm 0.0 \mathrm{~mm}, 2.1 \pm$ $0.1 \mathrm{~mm}$ and $3.1 \pm 0.4 \mathrm{~mm}$, respectively (Table 1). The diameter increased with age. Kelany et al. (1993) reported in Hy-line and Dandrawi chicken $0.97 \mathrm{~mm}$ at 12 weeks of 
age. The present study shows at 23 weeks a diameter double the $1.2 \mathrm{~mm}$ reported by Kelany et al. (1993) in Hy-line chicken.

Table 1. Mean Length, weight and diameter of vagina in ISA brown chickens ( $\mathrm{n}=21)$ Mean \pm S. D.

\begin{tabular}{l|c|c|c}
\hline \multicolumn{1}{c|}{ Age groups } & Length $(\mathrm{cm})$ & Weight $(\mathrm{gm})$ & Diameter $(\mathrm{mm})$ \\
\hline 3-weeks & $0.3 \pm 0.1$ & $0.0 \pm 0.0$ & $0.4 \pm 0.0$ \\
23-weeks & $6.0 \pm 0.1$ & $1.0 \pm 0.0$ & $2.1 \pm 0.1$ \\
46-weeks & $6.1 \pm 0.3$ & $2.5 \pm 0.1$ & $3.1 \pm 0.4$ \\
\hline
\end{tabular}

Histology and Histochemistry

Mucosal folds

The mucosal folds or villi were short and tongue-shaped at three weeks, elongated at 23 weeks and at 46 weeks numerous and elongated (Figs. 1 - 3).

\section{Lamina epithelia}

The lamina epithelia of the vagina were composed of pseudostratified ciliated columnar epithelial cells at each age (Figs. 1 - 3). Similar results were observed by Fujii (1963) in White Leghorn chickens. However, he did not mention the types of the epithelium.

\section{Lamina propria}

Unlike other segments of the oviduct the lamina propria of the vagina was composed of fibroblast, fibrocytes, lymphocytes, blood vessels, collagen fibres and lymphatics from 3 to 46 weeks old (Figs. 1 - 3).

Sperm host glands

Well-developed sperm host glands were in the lamina propria at 23 and 46 weeks within the folds (Fig. 2 - 3). Khan et al. $(1996,1999)$ similarly reported that the spermhost glands of White Leghorn chickens were tubular, and distributed in the lamina propria.

\section{Submucosa}

The submucosa of vagina was very scanty and continued with the lamina propria.

\section{Tunica muscularis}

The tunica muscularis was very thin at three weeks, but the muscle bundles with collagen fibres were developed at 23 and 46 weeks (Fig. 2 - 3). Similar study was done by Curties (1910); Sacchi (1987). 
Serosa

The serosa was very thin at all stages.

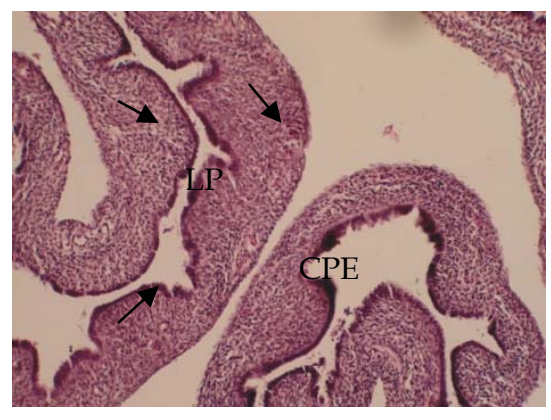

Fig. 1. The vagina of the oviduct of ISA brown Chickens at three weeks showing ciliated pseudostratified columnar epithelium (CPE) and huge lymphocytes (arrows) in the lamina propria (H\& E stain, 20x)

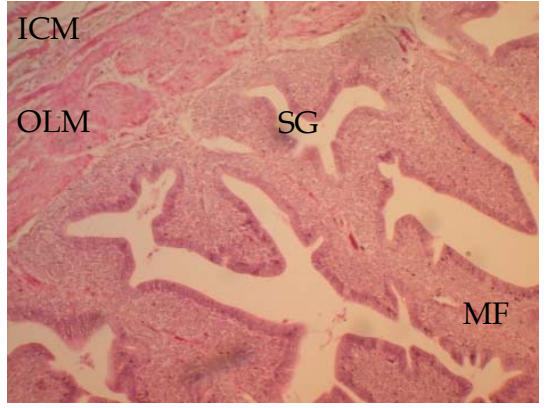

Fig. 2. The vagina of the oviduct of ISA brown Chicken at 23 weeks showing large number of mucosal folds (MF) with ciliated pseudostratified columnar epithelium. Huge number of sperm host glands (SG), developed tunica muscularis (TM): inner circular (ICM) and outer longitudinal muscular layer (OLM) (H\& E stain, 20x)

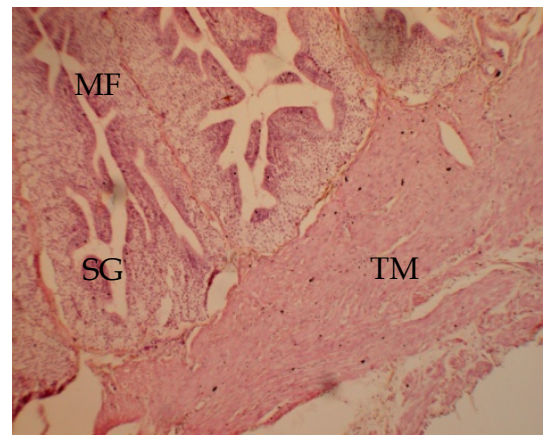

Fig. 3. The vagina of the oviduct of ISA brown chicken at 46 weeks showing large number of elongated mucosal folds (MF), huge number of sperm host glands (SG), and developed tunica muscularis (TM) with scanty lymphocytes (H\& E stain, 20x)

\section{Conclusions}

The vagina was a relatively short S-shaped tube between the uterus and cloaca. The length, weight and diameter of vagina increased with age. Immature vagina differed little in structure and development from the other regions of the oviduct but no glandular development was noticed. The mucosal folds become tongue-shaped to large elongated. The undifferentiated wall of vagina consists of low primary mucosal folds lined by simple columnar epithelium to a pseudo stratified ciliated columnar epithelium and a connective tissue layer underneath. Well-developed sperm host 
glands were in the lamina propria within the folds throughout the development. The most outstanding feature of vagina was a well developed tunica muscularis that contracts and helps oviposition

\section{Reference}

Ali MA 1973: Theory of Statistics, Vol. 2, Dhaka Book Mart, Dhaka, Bangladesh pp. $420-441$.

Curtis MR 1910: The ligaments of the oviduct of the domestic fowl. Bulletin of Maine Agricultural Experimentation Station, USA 176 1-20.

Federova NN 1987: Growth and development of the reproductive system in White Leghorn hens in different light systems. Sbor. Nanch. Trud., Moskovaskaya Veterinarya Akademiya, 128 37-40.

Fujii S 1963: Histological and histochemical studies on the oviduct of the domestic fowl with special reference to the region of utero-vaginal juncture. Archivum Histoogicum Japonicum 23 447-459.

Giersberg H 1922: Untersuchunger uber physiologic und histologic des Eileiters der Reptilien und Vogel: nebst einen Beifpag zur Faseganese. Z. Wisconsin Zoology 120 1-97.

Kelany AM, El-Shamy SA, Abou-Elmagd A, Selim AA, Kamel G, El-Bab MRF 1993: Studies on the development of the oviduct in high and low egg producing fowl $\mathrm{H}$ histological studies. Ail. Journal of Veterinary Medicine 282743

Khan MZI, Hashimoto Y, Konno Y, Kon Y, Iwanaga, T 1996: Development of Tlymphocyte subpopulation in the postnatal chicken oviduct. Cell and Tissue Research 284 317-325.

Khan MZI, Asaduzzaman ANM, Rahman A, Islam KhN 1999: Distribution and quantification of large granular lymphocytes (LGLs) in the sperm-host glands of chicken oviduct. Bangladesh Journal of Animal Science 28 47-51.

Romanoff AL, Romanoff AJ 1949: The avian egg. John Wiley and Sons, Inc., New York.

Sacchi M 1987: Contribuzione all'istologia dell' ovidotto del sanropsidi. Atti della societa Italiana di Scierze Naturali 30 273-309.

Taylor T, Hertelendy F 1960: Parallel distribution of calcium and citric acid in the oviduct of the hen. Nature 187 244-245.

Warren DC, Scott HM 1935: Physiological factors influencing the rate of egg formation in the domestic hen. Journal of Agricultural Research 51 565-572. 